\title{
Local implementation of the Family Health Program in Brazil
}

\author{
A implementação do Programa Saúde \\ da Família no cenário local
}

\footnotetext{
${ }^{1}$ Escola Nacional de Saúde Pública Sergio Arouca, Fundação Oswaldo Cruz, Rio de Janeiro, Brasil. 2 Escola de Serviço Social, Universidade Federal Fluminense, Niterói, Brasil.

Correspondence R. Magalhães Departamento de Ciências Sociais, Escola Nacional de Saúde Pública Sergio Arouca, Fundação Oswaldo Cruz. Rua Leopoldo Bulhões 1480, 9 o andar, Rio de Janeiro, $R J$ 21041-210, Brasil.

rosana@ensp.fiocruz.br
}

\begin{abstract}
This article discusses the implementation of the Family Health Program in the municipalities of Camaragibe, Aracaju, São Gonçalo, and the Federal District of Brazil, aiming to identify possible interfaces between the program's shaping and different incentives structures, the local health system's case-resolving capacity, experiences with social participation, and accountability mechanisms. The article shows that aspects related to the constitution of local health systems in terms of the quantitative and qualitative supply of services, technical and management training within the Municipal Health Department, investment in other levels of care, and local political traditions are crucial variables for understanding the diversity of experiences in the implementation of the Family Health Program.
\end{abstract}

Family Health Program; Policy Making; Health Public Policy; Decentralization
Rosana Magalhães 1

Mônica de Castro Maia Senna 2

\section{Introduction}

In the 1990s, within the context of public sector reform, political and administrative decentralization, and consolidation of the Unified National Health System (SUS), Brazil implemented a series of nationwide measures focused on guaranteeing stable funding of the health sector, healthcare quality improvement, universal access, and strengthening of public management. As part of this process, the Family Health Program (FHP) emerged as a perspective for reorienting the healthcare model, aimed at ensuring greater case-resolving capacity in the health services, promotion of social control, and closer links between families and the health teams. However, consistent research on the limitations and advances of the FHP has required an understanding of the various circuits comprising the local scenario (in terms of its epidemiological, political, institutional, and local participatory characteristics) which influence the program's organizational design.

Thus, understanding a social program's implementation as a non-linear learning process permeated with conflictive flows and often contradictory reorientations, the perspective of studying and discussing experiences with FHP implementation in the Brazilian municipalities (counties) of Camaragibe (Pernambuco State), Aracaju (Sergipe State), São Gonçalo (Rio de Janeiro State), and the Federal District, does not 
seek to evaluate the goals and objectives reached in these municipalities, but to help identify the influence of the various socio-political scenarios and the profiles of stakeholders in designing the local intervention. The effort is thus to emphasize the political dimension in the implementation of social programs and the relevance of various levels of support, accountability, and adherence for understanding the thrust of government action. Meanwhile, the comparison with so-called "contextual variations" 1 is intended to reclaim the specificities of each municipal reality. Thus, our analysis of the implementation of the FHP in the selected municipalities is based on the reflection concerning local contingencies, synergies, and specificities.

The information analyzed here was obtained through the study entitled Evaluation of the Implementation of the Family Health Program in Large Brazilian Cities - Ten Case Studies, coordinated by the Nucleus for Political and Social Studies in Health (NUPES), National School of Public Health (ENSP), Oswaldo Cruz Foundation (FIOCRUZ), with support and funding from the Brazilian Ministry of Health, Department of Basic Care, through the Project for the Expansion and Consolidation of Family Health (PROESF). The fieldwork was conducted from April to July 2002 and included the following methodological procedures: (a) data surveys in the Brazilian Institute of Geography and Statistics or National Census Bureau (IBGE), Department of Information and Information Technology of the Unified National Health System (DATASUS), Inter-Agency Health Information Network (RIPSA), and Basic Care Information System (SIAB) to characterize the demographic, socioeconomic, and health services supply conditions in the respective municipalities; (b) semi-structured interviews with the municipal health secretaries and local FHP coordinators; and (c) survey of the minutes of the Municipal Health Councils including discussions of the FHP implementation stages in order to systematize information on their social control work in structuring and monitoring the program.

\section{Basic care and the Family Health Program}

After a long tradition of prioritizing hospital care and fee-for-procedure financial mechanisms, since the late 1990s Brazil's health policy has undergone an important turnaround whereby basic care has concentrated a series of efforts, programs, and investments, creating Federal capitation financial incentives transferred to the municipalities.
One of the central strategies in this process was the adoption of a Minimum Basic Healthcare criterion, consisting of an amount of funds targeted for basic healthcare procedures under municipal control, such as immunization, physician consultations, and prenatal care, among others. The changes introduced under this minimum health package are accompanied by a set of other measures aimed at strengthening basic care and introducing changes in the healthcare model. However, adoption of the FHP definitely occupied an outstanding place among the Federal government's induction mechanisms for prioritizing basic care. In addition to the fixed per capita amount, the basic package established a variable amount (variable Minimum Basic Healthcare) based on the number of FHP teams implemented and according to the percentage of the municipality's population covered by the program.

Initially, the Federal government was in charge of implementing the Community Health Agents Program, an experience that had already been developed successfully in the North and Northeast of Brazil since 1991, aimed at extending coverage to rural and peripheral urban populations. Since 1994, in a context of intense mobilization of municipal health secretaries from all over the country in favor of basic care, the Federal government began implementing the FHP as one of the main mechanisms for reorganizing the Unified National Health System and for reorienting the healthcare model.

The healthcare model as proposed in the FHP principles and guidelines was characterized by an expanded vision of the health-disease process, intended to transcend the "biologizing" and curative bias and place the family and its context at the center of healthcare. The notion of territory, i.e., the strategy of linking the health team to a spatially demarcated population, is crucial for fostering greater accountability on the part of health workers in relation to the registered families, transformation of the traditional health intervention model, and organization of the demand 2

\section{The Family Health Program in the municipalities: unique and interdependent characteristics}

The success of the MoH induction strategy can be identified by the number of FHP teams set up in the country: data from Sousa et al. 3 show that in December 2000, the FHP was operating in 3,090 of Brazil's 5,500 municipalities, with a total of 10,473 teams, covering $22 \%$ of the total 
population. However, profound differences in the FHP design between municipalities should not be overlooked. Local financial, political, and administrative specificities require new explanatory variables beyond the overall reform process factors.

Thus, Camaragibe, Aracaju, São Gonçalo, and the Federal District have both important similarities and key differences in their epidemiological profile, institutional capacity, public administrators, and levels of social participation. Although the population in these municipalities and the Federal District is almost entirely urban (Table 1), there are significant differences in their population density, with heavy population concentration, especially in São Gonçalo and Camaragibe, thus posing challenges for ensuring access to health services and other public facilities.

In Aracaju and Camaragibe, according to the 2000 National Census 4, more than $50 \%$ of the inhabitants were less than 24 years of age. Table 2, analyzing the Municipal Human Development Index (MHDI), shows Camaragibe as the poorest municipality, with the lowest income and schooling levels.
As for sanitation, in Camaragibe $61.3 \%$ of households were connected to the public water supply, but fewer than $16 \%$ to the municipal sewage system. In Aracaju, 99\% of households were connected to the public water supply and $56 \%$ to the sewage system (38\% of the population used septic tanks or cesspools). In São Gonçalo, $76 \%$ of households were connected to the public water supply, but fewer than $40 \%$ to the public sewage system. In the Federal District, $86 \%$ of the household were connected to the public water supply, while $83 \%$ were connected to the sewage system, $10 \%$ had cesspools, and $6.5 \%$ septic tanks.

Analysis of the health services network in the selected municipalities also shows a heterogeneous supply of outpatient and hospital services. In Camaragibe, most outpatient units (70\%) were low-complexity, conducting basic healthcare activities. There was no supply of medium-complexity units in the municipality. All the hospital beds were private. According to data from the DATASUS Outpatient Data System (SIA-SUS), in $2001,80.5 \%$ of outpatient care in Camaragibe consisted of basic procedures. The concentration higher-complexity units (levels 2 and 3, accord-

Total population and demographic, geographic, and political administrative characteristics of selected municipalities and the Federal District, Brazil.

\begin{tabular}{|c|c|c|c|c|c|c|}
\hline \multicolumn{2}{|c|}{ State or Federal District } & \multirow{2}{*}{$\begin{array}{c}\text { Region } \\
\text { Northeast }\end{array}$} & \multirow{2}{*}{$\begin{array}{c}\text { Total } \\
\text { population } \\
128,702\end{array}$} & \multirow{2}{*}{$\begin{array}{c}\text { Density } \\
\text { (inhabitants/Km²) } \\
2,681.29\end{array}$} & \multirow{2}{*}{$\begin{array}{c}\text { Urban } \\
\text { population (\%) } \\
100.0\end{array}$} & \multirow{2}{*}{$\begin{array}{c}\text { Type } \\
\text { Metropolitan Area }\end{array}$} \\
\hline Camaragibe & Pernambuco & & & & & \\
\hline Aracaju & Sergipe & Northeast & 461,534 & $2,549.91$ & 100.0 & State Capital \\
\hline São Gonçalo & Rio de Janeiro & Southeast & 891,119 & $3,550.27$ & 100.0 & Metropolitan Area \\
\hline Federal District & Federal District & Central West & $2,051,146$ & 353.52 & 95.6 & Federal District \\
\hline
\end{tabular}

Source: Censo Demográfico 2000 [National Census] 4.

\begin{tabular}{|c|c|c|c|c|}
\hline & & \multicolumn{3}{|c|}{ Municipal HDI } \\
\hline & & Longevity & Education & Income \\
\hline Camaragibe & 0.747 & 0.761 & 0.847 & 0.633 \\
\hline Aracaju & 0.794 & 0.729 & 0.901 & 0.752 \\
\hline São Gonçalo & 0.782 & 0.742 & 0.896 & 0.706 \\
\hline Federal District & 0.844 & 0.842 & 0.935 & 0.756 \\
\hline
\end{tabular}

Source: United Nations Development Program/Institute of Applied Economic Research (IPEA)/ João Pinheiro Foundation/National Census Bureau (IBGE) 11. 
ing to the DATASUS classification) was greatest in Aracaju, São Gonçalo, and the Federal District. The supply of outpatient and hospital facilities with more complex procedures was greater in São Gonçalo and the Federal District. In São Gonçalo, the services supply was insufficient to treat the resident population, and the services were generally low-tech. The public hospital system was small and structured mainly for emergency treatment, while the private services outsourced by the public system accounted for more than $80 \%$ of the beds. In the Federal District, the proportion of public hospital beds was higher than the national average. Most of the Federal District's suburbs had regional hospitals for referral from the basic healthcare network. Even so, the network was disorganized, and basic care was not the actual portal of entry into the system.

The conditions prevailing under "municipalization" (decentralization to the municipal level) pointed to different levels of "institutional learning" 5 and autonomy in health services management. As shown in Table 3, Camaragibe was the only municipality authorized to practice so-called semi-autonomous management under the Basic Operational Norm of the SUS since 1993 (SUS/NOB/93) and fully autonomous management of the municipal system since 1998. Aracaju and the Federal District were only authorized under NOB/96, implemented in 1998. In 2002, São Gonçalo was still classified as autonomously managing basic health care only.

\section{Local implementation of the Family Health Program}

According to Skocpol \& Amenta 6, when social policies are implemented, they impact the decision-making process itself, since they change the public agenda and alter the negotiation and cooperation patterns between stakeholders. From this perspective, studying the implementation of public programs and policies can reveal new contours and socio-political innovations that alter, redefine, and retranslate the intervention's initial design. FHP implementation in Brazil was prioritized especially in small and medium-sized municipalities, where, according to the Ministry of Health's recommended standards, a small number of teams would be sufficient to cover nearly $100 \%$ of the population. In the large cities (especially those with more than 500,000 inhabitants), the FHP was implemented more incrementally, and there were numerous examples where it acted as a pilot project or focal program targeted at specific population groups.

\section{Camaragibe}

Camaragibe pioneered the implementation of the FHP in Brazil, beginning in 1994. Outside staff from the MoH and UNICEF, the mayor, and administrators from the Municipal Health Department progressively built a strong support base for the program. Since the late 1980s, Camaragibe had displayed a virtuous interaction between so-

Conditions in healthcare municipalization and management forms.

Selected municipalities and Federal District, Brazil, 2002.

\begin{tabular}{|c|c|c|c|}
\hline & $\begin{array}{c}\text { Initial } \\
\text { approval }\end{array}$ & $\begin{array}{l}\text { Level of approval } \\
\text { in } 2002\end{array}$ & $\begin{array}{l}\text { Administrative } \\
\text { continuity/ turnover } \\
\text { (number of terms) }\end{array}$ \\
\hline \multirow[t]{2}{*}{ Camaragibe } & 1994/Partially autonomous & & \\
\hline & management & 1998/GPSM & 3 \\
\hline Aracaju & 1998/GPAB & 2001/GPSM & 1 \\
\hline \multirow[t]{2}{*}{ São Gonçalo } & 1996/Partially autonomous & & \\
\hline & management & 1998/GPAB & 1 \\
\hline Federal District & 1998/GASE & 1999/GPSE & 1 \\
\hline
\end{tabular}

GPAB: fully autonomous management of basic care; GPSM: fully autonomous management of municipal system; GASE: expanded management of State system; GPSE: fully autonomous management of State system.

Source: Nucleus for Political and Social Studies in Health, National School of Public Health, Oswaldo Cruz Foundation, 2002. 
cial movements and public management, culminating in 1996 in the Participatory Management Program. The management model with residents participating through assemblies organized according to administrative districts and setting the priorities proved capable of hierarchically organizing the local demands in health, education, and affordable credit. The twice-yearly health assemblies, establishment of decision-making forums, and specific plenary meetings for discussing the implementation of the FHP managed to build a consensus concerning the need to reorient local healthcare, overcoming the main resistance and criticism by both the population and health professionals. Choice of priority areas for implementing FHP units resulted from discussion in the Municipal Health Council, with participation by mothers' clubs, neighborhood associations, senior citizens' groups, and community leaders.

Thus, creation of the FHP in Camaragibe as the portal of entry into the health system met one of the main objectives of healthcare reorganization, i.e., to overcome the juxtaposition and duplication of activities. Territorial management of the program guaranteed the debate on common objectives and the development of integrated actions. However, in 2002 the municipality still experienced major difficulties in building a complex, articulated healthcare network, capable of meeting the diverse demand. Table 4 summarizes the trends in FHP coverage in Camaragibe from 1994 to 2001.

The coverage ensured the municipality the last MoH incentives bracket per FHP team/year. However, according to the Municipal Health Secretary, in 2002 the funds transferred by the $\mathrm{MoH}$ only covered some one-third of FHP costs. Financial constraints also hindered more specialized procedures and tests, given the lag in the table recommended by the MoH: "In Pernam- buco, there is no specialized category or health professional performing ultrasound that can be purchased according to the table, so what am I supposed to do?" (Municipal Health Secretary, Camaragibe).

Although organization of specialized medical facilities and units for more complex tests attempted to meet the demand for mediumcomplexity care, the supply remained insufficient. Wage parity between FHP teams and other professionals in the healthcare network, like psychologists, occupational therapists, and speech therapists became an important strategy for ensuring adherence and commitment to the program. Meanwhile, the professionals were not hired for the FHP team directly, but through medical cooperatives. Physician turnover was high, and since the majority lived in the State capital, Recife, when the FHP was implemented there it created another difficulty for retaining physicians in Camaragibe. Administrative continuity, collective discussion of local health policy, and a tradition of accountability proved important for consolidating the FHP. Integrated management and good performance by community health workers, although overburdened in many areas, guaranteed the program's significant expansion and high coverage. However the precarious network of medium and high-complexity services created serious obstacles for ensuring a referral and counter-referral flow, to the point of becoming an impasse for the improvement of the local health system.

\section{Aracaju}

In Aracaju, unlike Camaragibe, the turnover in the municipal administration in 2001 and the resulting break in administrative continuity in the FHP generated a re-discussion of the program's guidelines (it was originally implemented

Teams, families enrolled, and population coverage. Family Health Program (FHP), Camaragibe, Pernambuco, Brazil, $1994-2001$.

\begin{tabular}{|c|c|c|c|c|c|}
\hline & $\begin{array}{c}\text { October } \\
1994\end{array}$ & $\begin{array}{c}\text { December } \\
1998\end{array}$ & $\begin{array}{c}\text { December } \\
1999\end{array}$ & $\begin{array}{c}\text { December } \\
2000\end{array}$ & $\begin{array}{c}\text { December } \\
2001\end{array}$ \\
\hline Number of family health teams & 4 & 19 & 28 & 31 & 32 \\
\hline Number of families enrolled & 3,759 & 24,882 & 26,353 & 29,165 & 34,153 \\
\hline Mean number of families/Team & 940 & 1,310 & 941 & 941 & 1,067 \\
\hline Population covered by the FHP (\%) & & 76.0 & 78.0 & 79.0 & 81.0 \\
\hline
\end{tabular}

Source: Municipal Health Department, Camaragibe, 2001. 
in 1998). One key criticism of the previous FHP implementation concerned the fragmentation of activities and limited investment in the healthcare model change proposed by the FHP: "When we took over here, we got a hot potato, since the FHP was atomized, implemented in islands in the middle of nowhere. The units that were not turned into FHP did not receive any investment. A wager was made: FHP or nothing. And the people turned to the FHP, but the program failed to provide treatment, because the people weren't enrolled in it" (Municipal Health Secretary, Aracaju).

The population's strong resistance to the program, especially in neighborhoods where there was a greater supply of traditional basic health clinics and specialists in pediatrics and clinical medicine, became an important issue that had to be solved.

Thus, in 2001, some 41 preliminary health conferences were held with users, managers, FHP teams, and the community. These meetings provided the basis for creating local health councils, having identified the main obstacles to health services access and established agreements for local investment. Adherence by health professionals was one of the main issues faced in the implementation of the FHP in 1998 and extending over the years. Still, according to the Municipal Health Secretary in 2002, low adherence to the FHP by physicians was still an important obstacle: "I have more physicians than I need to implement all the 120 [FHP] teams that would cover 85 to $90 \%$ of Aracaju. I have these physicians on the payroll, but they don't join the program" (Municipal Health Secretary, Aracaju).

The 40-hour workweek and the precarious labor relations (for the outsourced professionals) hindered the physicians' commitment and adherence to the program. However, nurses saw the FHP as a possibility for substantial wage improvement: "Conditions for nurses under the FHP are better, since they earn approximately 40 to $50 \%$ more than the going market wages" (Municipal Health Secretary, Aracaju).

In fact, all the nurses working in the FHP in Aracaju in 2002 were public employees from the municipal health network.

Technical consultancy from universities, especially from the public health physician and professor from the State University in Campinas (UNICAMP), Emerson Elias Merhy, as well as the presence of activists from the health reform movement, contributed to a unique emphasis on aspects pertaining to the shaping of the health care model. Beginning in 2001, Aracaju attempted to solve the tension involved in establishing universal access to the health services network, with "shelter, ties, accountability, and autonomy" as the key priorities. An analysis of FHP coverage in Aracaju shows an increase in the number of FHP teams and units from 1998 to 2001 (Table 5).

Implementation of the FHP in Aracaju since 2001 was marked by the challenge of "listening attentively to all those who come to the unit". The FHP units thus sought to improve the capacity to direct individuals to individual care or to programmed action, training professionals for both practices, even though this did not mean scheduling duty to treat the spontaneous demand or establishing shifts for the programs.

"Some problems occur out in the community and don't reach the unit, but they require intervention by the team" (Municipal Health Secretary, Aracaju).

\section{São Gonçalo}

As shown in Table 6, one peculiarity of the FHP in São Gonçalo is its size, both in terms of the number of teams set up simultaneously (some 170) and the population to be covered (some 580 thousand inhabitants, or $70 \%$ of the total population).

Table 5

Teams, families enrolled, and population coverage. Family Health Program (FHP), Aracaju, Sergipe, Brazil, $1998-2001$.

\begin{tabular}{|c|c|c|c|c|c|}
\hline & $\begin{array}{c}\text { December } \\
1998\end{array}$ & $\begin{array}{c}\text { December } \\
1999\end{array}$ & $\begin{array}{c}\text { December } \\
2000\end{array}$ & $\begin{array}{c}\text { December } \\
2001\end{array}$ & $\begin{array}{l}\text { April } \\
2002\end{array}$ \\
\hline Number of family health teams & 12 & 14 & 48 & 64 & 72 \\
\hline Number of families enrolled & 9.482 & 11.831 & 35.693 & 44.823 & 50.182 \\
\hline Mean number of families/Team & 790 & 845 & 743 & 700 & 697 \\
\hline Population covered by FHP (\%) & 9.4 & 10.1 & 32.6 & 38.3 & 52.4 \\
\hline Family health units & 9 & 10 & 22 & 27 & 29 \\
\hline
\end{tabular}

Source: Basic Care Information System and Municipal Health Department, Aracaju, 2002. 
Number of family health teams and population coverage. Family Health Program (FHP), Federal District, Brazil, $1999-2002$.

\begin{tabular}{lcccc}
\hline & December & December & December & April \\
& 1999 & $\mathbf{2 0 0 0}$ & $\mathbf{2 0 0 1}$ & $\mathbf{2 0 0 2}$ \\
\hline Number of family health teams & 121 & 60 & 68 & 51 \\
Population covered by FHP (\%) & 21.2 & 10.1 & 11.2 & 8.2 \\
\hline
\end{tabular}

Note: estimated from figures used by the Ministry of Health to calculate coverage for setting incentives brackets

to transfer Federal budget funds to the municipal level.

From this perspective, São Gonçalo can be considered a pioneer in the implementation of the FHP on a large scale in an area with a high urban concentration. According to local health administrators, the FHP aimed to reorganize the healthcare model so as to reverse the longstanding (and dramatic) epidemiological indicators in São Gonçalo and restructure a historically disorganized health care system. Given the persistent disorganization and insufficient supply of services, in the opinion of municipal administrators, the FHP strategy would only produce an impact on a large scale; hence the political choice to simultaneously implement some 170 FHP teams.

According to the system's managers, the FHP was expected to be a mechanism for expanding funds for the sector, given the $\mathrm{MoH}$ incentive. By covering $70 \%$ of the population with the FHP, São Gonçalo is included in the highest financial incentive bracket and is the municipality in the State of Rio de Janeiro that receives the most funds for the program 7 .

A crucial decision-making aspect in FHP implementation in São Gonçalo is the program's priority on the local agenda. The FHP was one of the key planks in the platform of the mayor who took office in 2001 and raised the perspective of innovation in municipal management, with the program as the prime example of changes in the health sector. The Family Health Program is headed by a woman physician who enjoys great prestige in the field of public health, but without any prior political or institutional link to São Gonçalo. It is emblematic that the Municipal Health Secretary is from outside the municipality. Unlike other municipalities with a certain participatory vocation, the FHP in São Gonçalo had no institutional political tradition to leverage this process. The municipal public machinery, marked by systemic ineffectiveness and inefficiency, evidenced the strong prevalence of pork-barrel arrangements in the relationship between the municipal Executive and Legislative branches and in the relationship between these powers and local civil society, as well as a fuzzy distinction between the public and private spheres. Contributing to this situation is the weak political organization of civil society, even in relation to the Municipal Health Council.

The main source of support for the FHP was the mayor himself, who granted total autonomy to the Municipal Health Department to conduct the process. The direct relationship between the Municipal Health Department and the MoH obviated any intermediation by the State Health Department, whose most important participation in the implementation of the FHP in São Gonçalo was to submit the project for discussion and approval by the so-called Bipartite Inter-Managers Commission and provide support from the State training division for selection and introductory training of the family health teams. The São Gonçalo FHP was also discussed and approved by the City Council and Municipal Health Council without any major restrictions.

The composition of the program's coordinating body, linked to the office of the Municipal Secretary, included a physician from the $\mathrm{MoH}$, a nurse from a neighboring municipality, two nurses who were already working in São Gonçalo in the Comprehensive Family Care Program, and a physician from the National Health Foundation (FUNASA) who also had previous experience in São Gonçalo. When this coordinating body was set up it virtually deflated the Superintendency of Collective Health (SUSC) in terms of its protagonist role in basic health actions in the municipality. The health professionals in the SUSC were upset at not having been invited to participate in the discussion and definition of the FHP in São Gonçalo. The new municipal health manager opted to turn the existing basic health units into FHP units. The health professionals who worked in these units were transferred to other services, especially the First Care Clinics (PAMs), while the FHP teams began enrolling the families in their coverage areas. According to interviews, this process sparked reactions by some neighborhood 
associations and City Council members, due both to the transfer of physicians and lack of clinical care during the enrollment phase.

Adherence to the FHP by health professionals from the Municipal Health Department was low, especially among physicians, which can be explained by the 40-hour workweek demanded by the program, in contrast with the wages, and the skepticism towards the FHP and its potential for causing any impact on local health. The rare physicians, nurses, and nursing technicians who opted for the FHP were submitted to a selection process along with other candidates (and received extra points because they were already affiliated with the municipality). Those who passed the selection process kept their employment relationship with the municipal government and received a wage bonus.

In contrast with the municipality's pork-barrel tradition (in which municipal civil service positions were filled through local political tradeoffs), a broad public admissions process was conducted with participation by professionals from the FHP training center, Ministry of Health, State Health Department, Rio de Janeiro State University (UERJ), and Salgado de Oliveira University (UNIVERSO). This strategy succeeded in neutralizing the nepotistic pressures by local politicians to name protégés for jobs in the FHP, especially community health workers.

In September 2001, the Municipal Health Secretary was dismissed and replaced by another physician, the owner of one of the largest private clinics in the city. This fact discredited him for the job, and after only three months he was replaced by his cousin (another physician and a City Council member since 1993). These constant changes in the Municipal Health Department caused great instability in the FHP policy and hindered the continuity of the project originally designed in São Gonçalo.

One of the first initiatives by the new Health Secretary was to bring the basic clinical specialists back to the family health units, after they had been transferred to other services. According to the Municipal Health Secretary, this re-transfer strategy was a response to resistance by the communities to the abrupt way in which the FHP was implemented. The idea was to maintain both models in a single unit in order to make a slow, gradual, and negotiated transition from the previous model to the FHP. “... Before, [no specialists] were kept, they were transferred, and that was that. But due to complaints by the community, now we're testing keeping the specialists until they [the community] get used to the family physician, and then we'll [transfer the specialists] gradually" (Municipal Health Secretary, São Gonçalo).
However, in practice this has led to duplication of actions and a reversal in the previously proposed model, to the extent that the family health team meets the scheduled demand, while the spontaneous demand is left to the other health professionals. An important weakness in the FHP in São Gonçalo is the lack of technical and management capability in the Municipal Health Department. The lack of mechanisms for monitoring and controlling the workload of the team members left room for the adoption of infamous stratagems for glossing shifts, with obvious negative repercussions on the quality of care provided. Theoretically, a supervisory team was supposed to exercise this control, providing technical supervision and managing human resources. However, the five-member supervisory team (medical specialists and nurses) was unable to cover the 179 teams, spread throughout the municipality. This weak management aggravated the limited ability of both civil society and the Municipal Health Department to intervene in the decision-making process. The Municipal Health Department has taken a formal and bureaucratic approach, merely reviewing cases that involve medium and high-complexity individual exams and clinical consultations. Organized civil society in the municipality is rife with nepotistic and paternalistic relations, thus representing more of an area for mutual pre-election back-scratching than a truly inclusive public sphere. Another crucial aspect is the relationship between basic care and other levels in the healthcare system. In São Gonçalo, there is a major deficit of medium and high-complexity services and an enormous private sector outsourced by the National Health System, accounting for more than $80 \%$ of the local hospital beds. This predominance has undermined public management in negotiating with (and regulating) the private sector. In actual practice there is no hierarchically organized health system, and there is thus no definition of the portal of entry into the municipal component of the National Health System. Even after the FHP was implemented, the spontaneous demand at various health establishments still prevails, and the portal of entry is still primarily through the emergency services.

\section{Federal District}

The FHP was implemented in the so-called "satellite cities" or working-class suburbs of Brazil's Federal District (Greater Brasilia) in 1999, when a new party coalition (in opposition to the previous administration) took office. A previous experience in 1997, similar to the FHP and called the Home Health Program, had been implemented 
in the Federal District, and by 1998 some 280 teams were operating in the various satellite cities and in health units set up in rented homes in the coverage area.

With the change in government administration, the Home Health Program was eliminated and all the health professionals were fired. According to the current Health Department managers, the agreement that had been signed with a public interest civil society organization (the Candango Institute for Solidarity) to hire personnel for the Home Health Program was about to expire and could not be renewed due to legal issues. Besides, the high wages and rental of the health units inflated the program's costs, thereby justifying the elimination of the Home Health Program, according to the current administration. Elimination of the program and subsequent implementation of the FHP proved to be a conflictive process, with major resistance by both health professionals and users. The Federal District Health Council also came out publicly against the extinction of the agreement with the Candango Institute and its replacement by a management contract to implement the FHP. Despite such resistance, some four months after the Home Health Program was eliminated the FHP has been implemented, with 50 teams working in the satellite cities. Adopting a strategy to promote a change in the healthcare model, the FHP in the Federal District is intended to cover $100 \%$ of the population in the satellite cities in an estimated three-year period. Implementation of the first teams attempted to cover the areas with the most difficult access to health services, although political issues were also taken into account in this selection. However, there are now areas previously covered by the Home Health Program that still lack FHP teams, thus drawing criticism by the population.

The FHP has faced major resistance by a wide variety of social actors linked to the health sector in the Federal District. Professionals from the original healthcare network questioned the high wages received by the Home Health Program employees. However, when new professionals were hired by the FHP with wages comparable to those of the original network, the resistance persisted. One important criticism involves hiring without a public admissions process, casting doubts on the professional qualifications of the FHP teams. But the main resistance from the career professionals is due to the focus on medium and highcomplexity care to the detriment of basic care. As stated by an administrator from the Federal District Health Department: "Our own colleagues from the health field have a hospital-centered culture, and think that the Family Health strategy and basic care are a waste of funds. So the majority [of health professionals] thinks that the funds should go to high and medium complexity rather than basic care."

This stance also predominates among regional health administrators, as expressed by transferring FHP physicians to cover shifts in the area's hospitals when there's a staff shortage. One of the main problems with the FHP in the Federal District is to retain professionals, especially physicians. The wages are not sufficiently attractive to foster adherence to the program, and the intense process of ongoing team training also fails to retain these professionals. The workload and working as GPs also mark the resistance to the FHP, in addition to the precarious job stability. To illustrate the size of the problem in the Federal District, of the 134 teams in April 2002, only 51 were complete and thus qualified according to the MoH. This situation even affects the qualifications of the oral health teams and the amount of funds transferred to the District Health Department for the program. The vast majority of the physicians working in the FHP are thus either recent graduates or retirees from the public health system.

One peculiarity of the Federal District is the extensive and complex public healthcare system, distributed throughout the satellite cities and consisting of FHP units and health centers and hospitals, organized hierarchically. In this context, the FHP provides the portal of entry into the system, while referral to more complex services is formalized, although unevenly in the various regions. Generally speaking, monthly quotas are set for the specialties, and for some of them there is a great demand by the population from other cities and even from other States in search of the specialized services in the Federal District, which further overloads the local health system and hinders the referral from basic care to other levels of complexity.

\section{Final remarks}

The territorial organization of social policies and the establishment of comprehensive interventions in a single population segment also tend to achieve greater impact and efficacy. Health inequalities analyzed on the basis of demarcated social spaces can facilitate the combination of actions with a universalist format and those that discriminate positively. The interaction between different social concepts and subjects also produces unique contours in the local FHP. In practice, the so-called "policy-makers" do not control all the variables and processes 8 . Thus, the limited flexibility in the incentives structure tends to 
create conflicts that in the final analysis impact the implementation of teams and consolidation of the program in the municipalities. Camaragibe and Aracaju, which attempted to set up coordinating bodies for the FHP that were integrated with basic care (with territorial organization and converting the health units, avoiding the maintenance of different health care logics), tended to improve the quality of care. As indicated by Tendler 9, the management of daily problems, supervision, and flexibility of actions are key issues for the success of the intervention. However, despite the advances in the FHP in these municipalities, there are also some important "critical bottlenecks". Camaragibe has no supply of more complex services or mechanisms for referral to other municipalities, thus hindering the comprehensiveness and case-resolving capacity of the health actions. Meanwhile, Aracaju still faces limitations for solving the spontaneous demand issue and thus ensuring appropriate handling of cases. On the other hand, in São Gonçalo and the Federal District the implementation of the FHP was unable to overcome the existing weaknesses in the local healthcare networks, even in relation to basic care. In São Gonçalo, adoption of the FHP without more consistent interaction with the various influential social actors from the health sector agenda proved incapable of producing a social support base for the program. The municipality's administrative weakness and political administrative instability (with successive turnover in the Municipal Health Department administrators) had negative repercussions on the shaping of a health care project in the medium and long term. The health services organization is still chaotic, without a clear definition of the portal of entry into the system or the health units' treatment profile. In the Federal District, resistance to the FHP came in various forms, from the wage issue to the lack of priority for basic care. In fact, the hospital-centered concept was hegemonic and focused the heaviest resistance to the FHP. In the Federal District there was actually a considerable supply of public hospital services, which even attracted patients from other municipalities and States. Nevertheless, access to health services was still quite difficult. In this context, the FHP might have represented a real possibility for extending local health care coverage.

All the experiences analyzed here suffer from persist obstacles to the integration of basic care with other tiers in the system, hindering the comprehensiveness and case-resolving capacity of health actions. They also face the challenge of building a solid commitment in the healthcare field at the three levels of government. Limited financial and operational support from the State Health Department was a recurrent issue in the words of local health system managers. The problem actually relates to the lack of definition in the State Health Department in relation to priority criteria and parameters for funding basic care 10 .

Studying the selected cases also helped consolidate the idea that beyond monitoring and follow-up of standards and rulings, it is crucial to strengthen the role of local health councils in the reorientation of health policy and implementation of the FHP. It is also important to strengthen integrated actions, discussed in the sphere of the health councils, since changes in the population's health conditions require reaching beyond sector-limited initiatives. The experiences with territorial management and integrated, multidisciplinary coordination have guaranteed greater case-resolving capacity in the actions implemented by the FHP in the target municipalities. Finally, the challenges to FHP implementation in the local scenario are of different types, and dealing with them requires taking the local historical, social, economic, and political conditions into account.

\section{Resumo}

Este trabalho busca discutir a implementação do Programa Saúde da Família (PSF) nos municípios de Camaragibe, Aracaju, São Gonçalo e Distrito Federal, de forma a identificar as possíveis interfaces entre a conformação do programa e as diferentes estruturas de incentivo, resolubilidade do sistema local de saúde, experiências de participação social e mecanismos de accountability constituídos. O estudo demonstrou que aspectos relacionados à constituição do sistema local de saúde em termos da oferta quantitativa e qualitativa dos serviços, capacitação técnico-gerencial no âmbito das Secretarias Municipais de Saúde, investimento nos outros níveis de atenção e a tradição política local são variáveis cruciais para a compreensão da diversidade de experiências de implementação do PSF.

Programa Saúde da Família; Formulação de Políticas; Políticas Públicas de Saúde; Descentralização 


\section{Contributors}

R. Magalhães conducted the fieldwork in Camaragibe (Pernambuco) and Aracaju (Sergipe), systematized and analyzed the data, drafted the article, and performed the final revision. M. C. M. Senna conducted the fieldwork in São Gonçalo (Rio de Janeiro) and the Federal District, systematized and analyzed the data, and participated in drafting the article.

\section{References}

1. Denis JL, Champagne F. Análise da implantação. In: Hartz Z, organizador. Avaliação em saúde. Rio de Janeiro: Editora Fiocruz; 2000. p. 49-85.

2. Viana AL, Dal Poz M. A reforma do sistema de saúde no Brasil e o Programa de Saúde da Família. Physis (Rio J) 1998; 8:11-48.

3. Sousa MF, Fernandes A, Araújo C, Fernandes MC. Gestão da atenção básica: redefinindo contextos e possibilidades. Divulg Saúde Debate 2000; 21:7-28.

4. Instituto Brasileiro de Geografia e Estatística. Censo demográfico 2000. Rio de Janeiro: Instituto Brasileiro de Geografia e Estatística; 2002.

5. Viana AL, Heimann L, Lima LD, Oliveira RG, Rodrigues SH. Descentralização e federalismo: a política de saúde em um novo contexto - lições do caso brasileiro. Ciênc Saúde Coletiva 2002; 7:493508.

6. Skocpol T, Amenta E. States and social policies. Annu Rev Sociol 1986; 12:131-56.
7. Ministério da Saúde. Sistema de informações em orçamentos públicos em saúde (SIOPS). http:// www.saude.gov.br (acessado em 19/Jul/2002).

8. Viana AL. Abordagens metodológicas em políticas públicas. Rev Adm Pública 1996; 30:5-43.

9. Tendler J. Bom governo nos trópicos: uma visão crítica. Rio de Janeiro: Editora Revan; 1998.

10. Sobrinho EJMA, Sousa MF. A tarefa: apagar os sinais vermelhos do PSF. In: Sousa MF, organizador. Os sinais vermelhos do PSF. São Paulo: Editora Hucitec; 2002. p. 155-70.

11. Programa das Nações Unidas para o Desenvolvimento/Instituto de Pesquisa Econômica Aplicada/Fundação João Pinheiro/Instituto Brasileiro de Geografia e Estatística. Atlas do desenvolvimento humano [CD-ROM]. Brasília: Programa das Nações Unidas para o Desenvolvimento; 2003.

\footnotetext{
Submitted on 14/Dec/2004

Final version resubmitted on 20/Jul/2005

Approved on 12/Aug/2005
} 